\title{
Study on Premature Failure of PV Systems in Malaysia using FMEA and Integrated ISM Approaches
}

\author{
Tan Dei Han ${ }^{1, *}$, Mohamad Rosman M. Razif ${ }^{1}$, and Shaharin A. Sulaiman ${ }^{1}$ \\ ${ }^{1}$ Department of Mechanical Engineering, Universiti Teknologi PETRONAS, 32610 Seri Iskandar, \\ Perak, Malaysia
}

\begin{abstract}
Solar photovoltaic (PV) systems has the potential of supplying infinite electricity from renewable energy to rural areas around Malaysia. Various preterm failures happening frequently on the system lead to its drop in efficiency and breakdown. Lack of studies on the system in Malaysia hinders the development in terms of operation and maintenance. There is no proper documentation relevant to the premature failure of the system in Malaysia. The main objective of this project is to study the nature of premature failure of stand-alone solar photovoltaic system in Malaysia in order to improve the operation and maintenance of the system. The present study would provide reference for proper planning on operation and maintenance of the PV system. The study was conducted base on expert's input and extensive literature survey. FMEA method and ISM approach are applied to analyze the data collected. Poor cooling system have the highest risk priority number. Poor workmanship is the least depending factor for premature failure to happen thus requires most attention. Highest driving force of premature failure is poor monitoring and maintenance. More focus should be given to these premature failure during the planning for operation and maintenance due to its severity and impact.
\end{abstract}

\section{Introduction}

Solar PV systems have been adopted and increasingly considered as a cost-effective mode for providing electricity access to off-grid areas [1]. It takes large investments and intensive infrastructures to electrify rural areas using traditional approaches, but it would be easier and more cost effective to implement renewable energy microgrids [2]. Solar energy is known to have the widest application in electricity generation out of all renewable energy technologies that can be used in decentralized application [3]. Every technology repair needs expertise from manufactures and thus the customers are forced to get help from agents or distributors of the solar panel [5. Inverters failure within solar PV system are found to be the most frequent incident [10]. The dominant failure mechanism in this IGBT modules is the bond wire fatigue [15].

\footnotetext{
*Corresponding author: tdhan26@gmail.com
} 
Even though the failure modes studied have different initial triggering factors, the final destruction of the PV inverter is almost always due to overheating [14]. While, number of cycles leading to the failure of the IGBT is influence by temperature, cycle amplitude and period etc [16]. This project studies the nature of premature failure of stand-alone solar photovoltaic system in Malaysia. By identifying the specific problems leading to the collapse of the system, this study will help improve the operation and maintenance of solar PV in Malaysia in the future. The study was conducted in Malaysia based on results from various solar PV company around Malaysia. The study of the nature and causes of the system failure is to eliminate risks that will jeopardize the efficiency of the system. Not much research and effort is being done to improve solar PV system in Malaysia. There is still no proper documentation relevant to the best operation and maintenance practice for solar PV systems in Malaysia. Therefore, study on the various preterm failure of the solar PV system is required to help produce useful guidelines for the systems' operation and maintenance.

\section{Methodology}

Targeted data to collect are the various details of premature failure of the PV system with specifications on their cause, effect, level of occurrence, significance and detection, etc. Besides that, it is also critical to know how different premature failures relate to one another. The data collected must be able to fulfill the requirements described in FMEA method [17] and ISM analysis [18]. One of the method is by conducting survey from the list of contacts for companies responsible in the assembling and installation of the solar PV system that can be obtained from the website of SEDA Malaysia (Sustainable Energy Development Authority of Malaysia). The main focus of the survey is to recognize contextual relationship among premature failures of the solar PV system. The data collected is for the purpose of analysis using ISM and FMEA method. Information was gathered by discussion with the following technicians and engineers from solar PV companies that focus in the installation, operation and maintenance of the solar PV system. The main purpose of the discussion is to help further the understanding of the result obtained from survey. By using available information from literature survey, data from survey and discussion with technicians and engineers, result can be analyze to properly obtain the conclusion of the project. Analysis is to be made on the data obtain with the aim to achieve the objective of the project. Failure mode and effect analysis (FMEA) method can be used to effectively organize the data obtained in order to form proper analysis. As shown in Figure 1 is the flow chart of the FMEA process. FMEA worksheet are then produced and reviewed. Another method used in this project for analysis is Interpretive Structural Modeling (ISM). As shown in Fig. 2 is the steps involved in completing the ISM method. The four symbols used for developing SSIM and the rules utilized for synthesis of initial reachability matrix are as shown in Table 1.

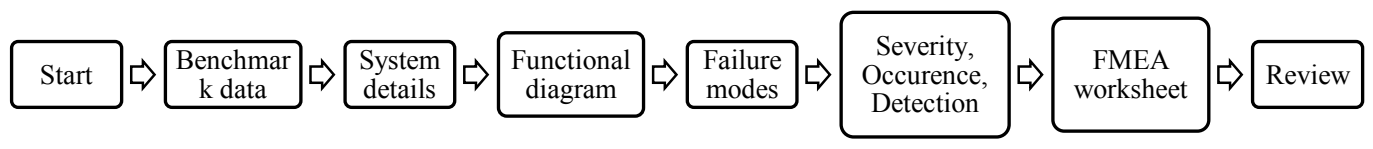

Fig 1: Block diagram representing FMEA process flow along this study

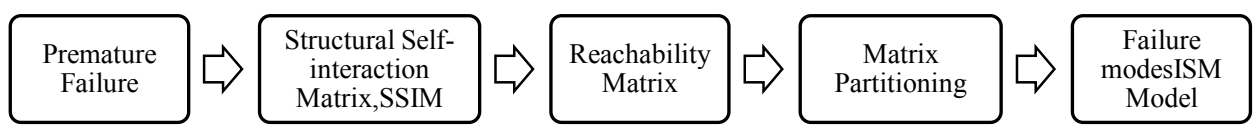

Fig 2: Steps involved in ISM method 
Table 1. Rules for SSIM and Reachability Matrix

\begin{tabular}{|c|c|}
\hline$\sum_{\substack{n \\
\infty}}$ & $\begin{array}{l}\text { V- When variable } i \text { help in achieving variable } j \\
\text { A- When variable } j \text { helps in achieving variable } j \\
X-\text { When variable } i \text { and } j \text { help in achieving one another } \\
\text { O- When variable } i \text { and } j \text { show no relation to one another }\end{array}$ \\
\hline 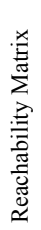 & $\begin{array}{l}\circ \text { The presence of V in SSIM indicates to use ' } 1 \text { ' in }(i, j) \text { entry and ' } 0 \text { ' in the }(j, i) \\
\text { entry in the reachability matrix } \\
\text { The presence of A in SSIM indicates to use ' } 0 \text { ' in (i,j) entry and ' } 1 \text { ' in the }(j, i) \\
\text { entry in the reachability matrix } \\
\text { The presence of X in SSIM indicates to use ' } 1 \text { ' in both }(i, j) \text { and }(j, i) \text { entry in the } \\
\text { reachability matrix } \\
\text { The presence of O in SSIM indicates to use ' } 0 \text { ' in both }(i, j) \text { and }(j, i) \text { entries in the } \\
\text { reachability matrix obtained for the premature failure of PV system. }\end{array}$ \\
\hline
\end{tabular}

\section{Result and discussions}

\subsection{Solar panel}

Vandalism happens very often on the solar panel. Vandalism such as the tossing of sharp and heavy object on the solar panel can cause the cracking of glass on the solar panel due to impact. The throwing of foreign object can happen from outside or within the fencing of the PV system. This is because some of the solar PV sites are not properly enclosed or locked. This can lead to the drop in efficiency of the solar panel, which directly slows down the electricity supply to load.

\subsection{Inverter}

There is a problem of charging and discharging issues when it comes to the inverter. In some cases, the reading from inverter might not be accurate and some of them might be illogical in reality. This might be due to the misuse of the inverter or the aging that happen on the components. In order to overcome this, technicians would usually take the necessary readings from the HCCU (hybrid control command unit). A cage is built around the inverter to avoid pest from entering since it can cause the disconnection inside the inverter.

\subsection{Diesel generator set (Genset)}

Generally, the diesel generator set (Genset) is the hardest part to maintain among all components in the solar hybrid PV system. One of this factor is that some supplies for the genset is hard to obtain here in Malaysia. From the visit to SK Kuala Mu and SK Pos Piah, it is observed that some of the internal screws within the genset came loose causing some component to fall out. Constant vibration of the genset which cause the loosening of the screws inside the genset.

\subsection{Battery}

The battery of the overall solar PV system is also damaged due to overheating of the node. This may happen due to the lack of distilled water in the battery. This mean that the battery is not being refilled properly which is indirectly caused by poor maintenance of the battery. However, another factor that can influence this damage is the poor ventilation inside the room which stores the batteries when the fan which keep the room cooled has malfunctioned. 


\subsection{FMEA method}

The ranking criteria developed respectively for the severity, the occurrence and the detection ratings [17]. The application of FMEA approach in Table 2 shows poor cooling system to be the factor to have the highest RPN. This is in line with the experience as discussed with some PV plant technicians. Second highest RPN is the equipment reliability, poor DC wiring connection, and non-optimum system design. This shows the significance of poor cooling system relative to other premature failures. However, there is not much difference between the first and second highest RPN shown in Table 2.

\subsection{ISM analysis}

Various premature failure of the PV system is identified from survey and discussion with technicians of PV company. Next, structured self-interaction matrix is prepared by making comparisons between the variables pair-wise. In the third step, initial reachability matrix is done by replacing the symbols with binary numbers. Reachability matrix can then be used to partition the matrix into different levels. Figure 3 shows the most depending premature failure in Level 1 which is power tripping while second most depending factor is poor equipment reliability. Figure 4 shows the ranking of driving power of premature failure. At level 1 is where driving factor is highest which is poor monitoring and maintenance. Level 9 consists of premature failures that has the least driving force such as increase of new shading element, cell cracking, soiling (dust), snail effect, power trip and over-discharged of battery banks.

Table 2. FMEA table

\begin{tabular}{|c|c|c|c|c|c|}
\hline & $\underline{\text { Potential failure mode }}$ & $\begin{array}{c}\text { Severity } \\
\text { rating }\end{array}$ & $\begin{array}{l}\text { Detection } \\
\text { rating }\end{array}$ & $\begin{array}{l}\text { Occurrenc } \\
\text { e rating }\end{array}$ & $\begin{array}{c}\text { Risk } \\
\text { priority } \\
\text { no. } \\
\end{array}$ \\
\hline \multirow{6}{*}{ 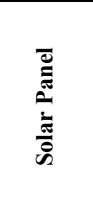 } & Increase of new shading element & 4 & 1 & 2 & 8 \\
\hline & Poor DC wiring connection & 4 & 5 & 1 & 20 \\
\hline & Soiling (Dust) & 3 & 1 & 5 & 15 \\
\hline & Cell Cracking & 2 & 3 & 1 & 6 \\
\hline & Degradation of solar panel & 3 & 2 & 2 & 12 \\
\hline & Snail Effect & 1 & 5 & 1 & 5 \\
\hline \multirow{12}{*}{ 齐 } & Poor Workmanship & 4 & 4 & 1 & 16 \\
\hline & Poor Monitoring \& Maintenance & 3 & 3 & 2 & 18 \\
\hline & Design Error & 3 & 2 & 1 & 6 \\
\hline & Non-Optimum system design & 5 & 4 & 1 & 20 \\
\hline & Remote monitoring and troubleshooting & 5 & 1 & 1 & 5 \\
\hline & Power Trip & 3 & 1 & 1 & 3 \\
\hline & Lightning (direct strike / induced) & 5 & 1 & 1 & 5 \\
\hline & Corrosion & 3 & 3 & 2 & 18 \\
\hline & Pest (Rats and Lizards) & 4 & 1 & 2 & 8 \\
\hline & Poor Equipment reliability & 4 & 5 & 1 & 20 \\
\hline & Degradation of DC cable & 3 & 2 & 1 & 6 \\
\hline & Poor cooling system & 4 & 3 & 2 & 24 \\
\hline \multirow{2}{*}{ Battery } & Over-discharged of battery banks (System abused) & 5 & 1 & 1 & 5 \\
\hline & Shortage of battery electrolyte & 5 & 2 & 1 & 10 \\
\hline \multirow[b]{2}{*}{ Genset } & Lack of Diesel fuel supply & 5 & 1 & 1 & 5 \\
\hline & $\begin{array}{l}\text { Long delivery time to deliver diesel fuel due to } \\
\text { remoteness of site }\end{array}$ & 5 & 1 & 1 & 5 \\
\hline \multirow{4}{*}{ 离 } & Dust on combiner box \& inverter & 2 & 2 & 1 & 4 \\
\hline & Problem with PV strings in combiner box & 4 & 1 & 1 & 4 \\
\hline & DC/AC SPD break down & 2 & 3 & 2 & 12 \\
\hline & DC fuse and MCB Breakdown & 2 & 4 & 1 & 8 \\
\hline
\end{tabular}




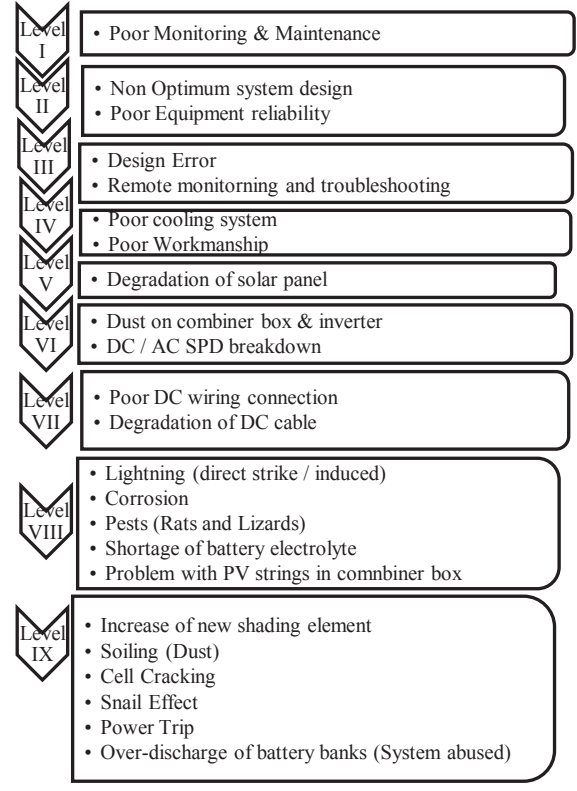

Fig. 3. Ranking of driving power of premature failure of PV system

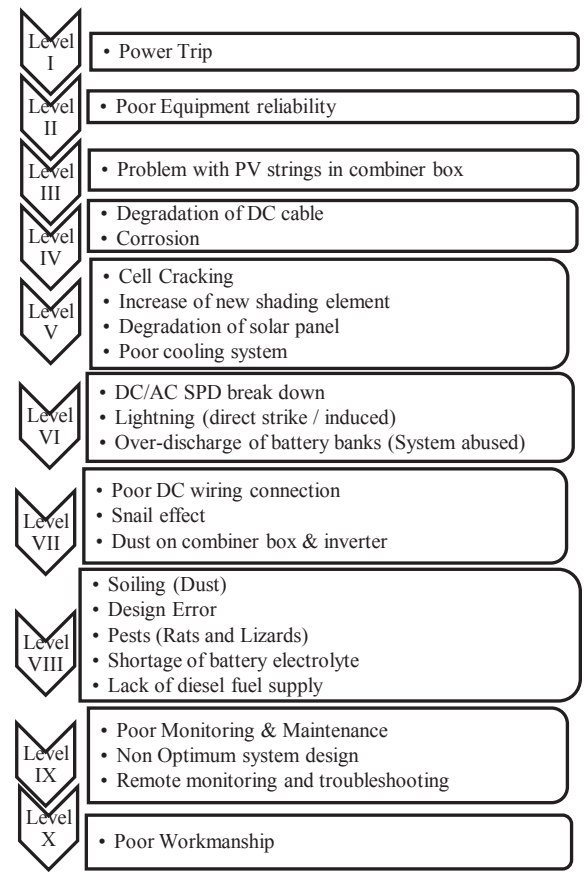

Fig. 4. Ranking of dependence power of premature failure of PV system

\section{Conclusions}

The present study has been conducted to investigate on the nature of premature failure of the solar PV system in Malaysia. Documented solution would help improve the operation and maintenance of solar PV system in the future. The following could be concluded:

1. The application of FMEA method shows poor cooling system to have the highest RPN compare to other premature failure.

2. While closely behind with second highest RPN is poor equipment reliability, poor DC wiring connection and non-optimum system design.

3. By understanding the significance of these factors, preventive actions require relevant personnel working in the field of PV system to take extra care to avoid problems of such significance.

4. From the analysis of ISM, poor workmanship is the least depending factor to occur while power tripping and poor equipment reliability have the highest depending factor. Failure of least depending factor requires the most attention and should be prioritize.

5. Highest driving force of premature failure is poor monitoring and maintenance. This driving factor is important as these premature failures is capable of affecting other components of the PV system, therefore more focus should be given to these during O\&M planning.

The authors would like to give a million thanks to Mechanical Engineering Department, Universiti Teknologi PETRONAS for their support and providing tuition fees for this conference. And also a great thanks to committee members of UTP-UMP-VIT Symposium on Energy Systems (SES) 2018. 


\section{References}

1. D. Palit and K. Bandyopadhyay, Econ Pol Wkly, 50, 7, (2015)

2. D. Gandini and A. T. de Almeida, Renewable Energy, 111, 275-283, (2017)

3. W. Zhou, C. Lou, Z. Li, L. Lu, and H. Yang, Appl Energy, 87, 9, (2010)

4. C. Whaley, National Renewable Energy Laboratory (NREL), (2016)

5. K. Jayaraman, L. Paramasivan, and S. Kiumarsi, Renewable and Sustainable Energy Reviews, 80, 562-571, (2017)

6. M. Perdue and R. Gottschalg, IET Renewable Power Generation, 9, 432-437, (2015)

7. C. Lupangu and R. C. Bansal, 73, 950-965, (2017).

8. L. R. Valer, A. R. A. Manito, T. B. S. Ribeiro, R. Zilles, and J. T. Pinho, Renewable and Sustainable Energy Reviews, 78, 1033-1043, (2017) 